\title{
AN INVESTIGATION OF THE INFLUENCES ON THE GEOCHEMISTRY OF STREAMS IN DOMINICA, LESSER ANTILLES: 2014-2017
}

DEXTER KOPAS, Beloit College

Research Advisors: Susan Swanson, Erouscilla Joseph, and Holli Frey

\section{INTRODUCTION}

The chemical makeup of stream waters is a reflection of the environment upstream. Two important tools in determining water provenance are stable isotopes $\left(\delta^{18} \mathrm{O}\right.$ and $\left.\delta^{2} \mathrm{H}\right)$ and major ion concentrations, both useful for determining environmental influences in tropical climates (Lachniet and Patterson, 2009, Goldsmith et al., 2010). Much is known about the relationships between environmental factors and stream chemistry in the temperate catchments of North America and Europe; however, little is known about tropical volcanic regions (McDowell et al., 1995, Johnson et al., 1997, ). This project will serve to give a general overview of the major environmental controls on stream stable isotope and major ion geochemistry in Dominica and, by extension, the surrounding Lesser Antilles considering multiple and potentially complex interactions of these factors. With a baseline knowledge of the current controls on chemistry, future changes to this baseline can be explored.

Located at the center of the Lesser Antilles archipelago, the island nation of Dominica presents an interesting study area to investigate the environmental influences on stream geochemistry in the tropics. The island features a population of 74,000, active volcanism, one of the world's greatest stream den-sities, with 350 streams over an area of $751 \mathrm{~km}^{2}$, and high precipitation rates up to $10,000 \mathrm{~mm} / \mathrm{yr}$ in the mountainous interior. Synthesizing data collected in projects led by Holli Frey over the last four years, this study aims to characterize the impact of environmental factors to stream water chemistry, examining precipitation patterns and hydrothermal activity
(Metzger et al., 2015; DeFranco et al., 2016; Metzger et al., 2016).

Several impacts are possible from climatic factors. The dominant wind direction in Dominica is east to west, with the interior mountains presenting a mild rain shadow. As rainout occurs in this direction, east coast precipitation may be more isotopically enriched than on the west coast (Lachniet and Patterson, 2009). At higher altitudes in the central mountains, lower temperatures may drive precipitation to be more isotopically depleted. If local rainout is an important control, then catchment precipitation may be inversely correlated with $\delta^{18} \mathrm{O}$. Tropical storms often have a source different from normal weather, such that a sudden rainfall event may temporarily alter the isotopic signature of surface streams (Good et al., 2014). Tropical Storm Erika, which hit Dominica in August of 2015, presents an interesting opportunity to test this relationship, having dropped over $500 \mathrm{~mm}$ of rainfall in a single day (Ogden, 2016). If any of these effects are significant, they should impact the isotopic signature of meteorically-fed surface waters.

At hydrothermal springs near volcanic centers, meteorically sourced water is altered through subsurface geothermal processes, wherein high temperatures encourage faster equilibration between water and bedrock. Downstream, rivers with hydrothermal sites in their catchments may be enriched in both $\delta^{18} \mathrm{O}$ and $\delta^{2} \mathrm{H}$, and the stream water may exhibit an ionic signature that is similar to the hydrothermal source. These effects should be proportional to the relative input of hydrothermally altered waters to a given stream and diminish going downstream from the hydrothermal source. 


\section{METHODS}

This study is primarily concerned with a four-year collection of stream and spring samples. From 2014 to 2017, annual samples were collected in June from a total of 104 water bodies. Samples were collected from streams, both near coastal outlets as well as upstream. Coastal samples were collected closest to the shore while remaining out of the influence of seawater. The major hydrothermal springs on the island were also sampled directly from orifices (Fig. 1).

The suite of 104 sample sites was classified depending on three criteria. In terms of hydrothermal influence, four categories are used. Samples from streams with at least one hydrothermal site in their catchment are classified as mostly meteoric with some hydrothermal input, or Hyd-met, while those without any hydrothermal sites upstream are classified as purely meteoric, or Met. This was determined using the placement of hydrothermal areas from Smith and Roobol's 2013 geologic map of Dominica in relation to stream basins in a geographic information system (GIS). Samples collected directly from hydrothermal pools are classified as hydrothermal, or Hyd. Samples are further differentiated into coastal ( $<2 \mathrm{~km}$ from the coast) and interior $(>2 \mathrm{~km})$ using GIS. To measure the rain shadow effects, coastal samples are split into either east and west, excluding those sites on the island's southern coast.

All water samples were analyzed for stable isotopes of deuterium and oxygen, and used to assess the influences of all possible environmental factors. Waters were sealed in glass containers with no air space. Thermo TC/EA (High Temperature Conversion Elemental Analyzer) measured $\delta^{2} \mathrm{H}$ concentrations, and a Delta $\mathrm{S}$ Mass Spectrometer and Ecotainer measured the concentration of $\delta^{18} \mathrm{O}$. Three in-house standards corrected the data, which were then related to VSMOW. For a local meteoric water line (LMWL), values are used for the Northeastern Caribbean from Govender (2013). Stable water isotope values were averaged for each sample site and plotted in Esri ${ }^{\mathrm{TM}}$ ArcMap GIS software based on their GPS-measured sampling location. Isotope values are quantified using quantiles and colored accordingly.
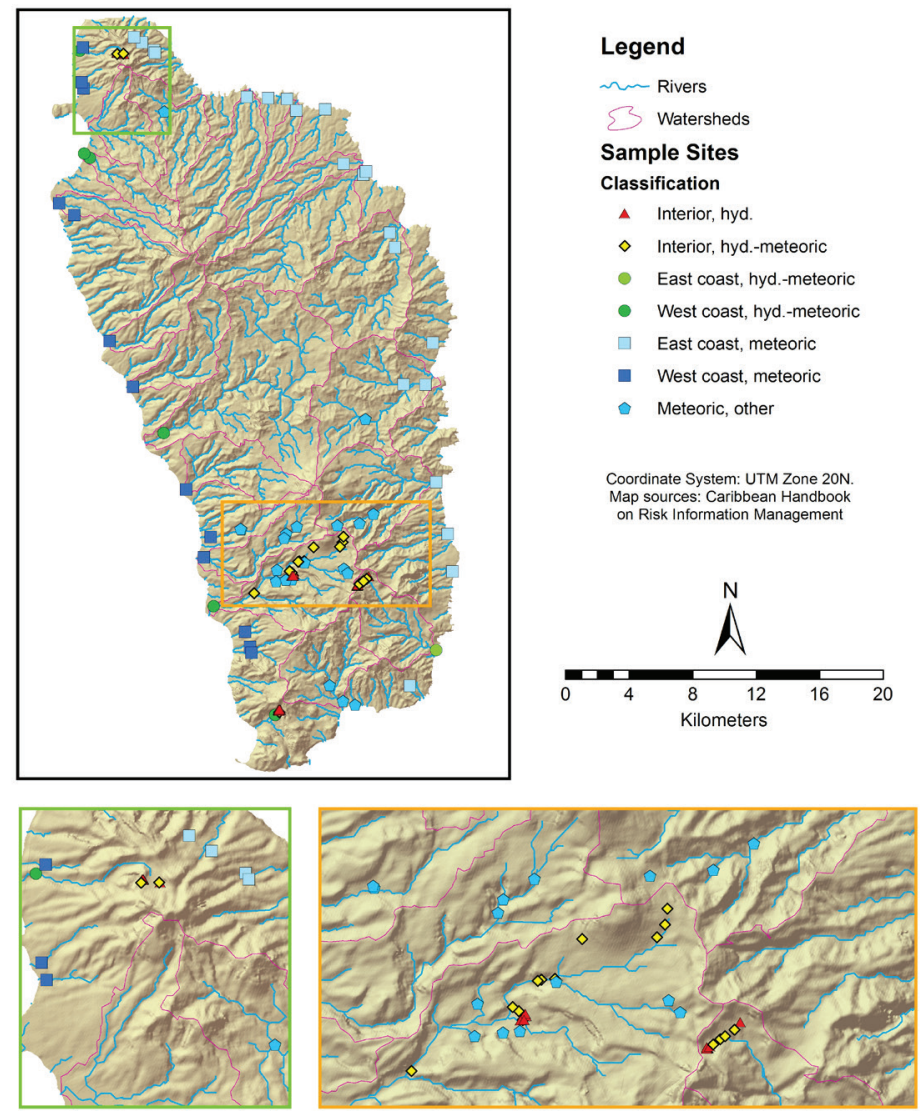

Figure 1. Map of the Dominica showing categorized sample locations.

To aid in assessment of wind direction, altitude, and storms, a contoured precipitation map from a 1967 soil and land-use report was digitized, using GIS to extrapolate values between contour lines. Stream catchments were imported to GIS, where the zonal statistics tool gave an average annual precipitation value associated with each stream catchment. To measure the impacts from tropical storms, a single event was examined. Tropical Storm Erika was the only major storm to pass significantly close to Dominica during the sampling period, passing by the island on August 27, 2015 and dropping over $500 \mathrm{~mm}$ of precipitation. The proceeding sampling occurred ten months later in June of 2016.

To further assess the influence of hydrothermal sources, major cations and anions were analyzed in addition to the previously discussed isotopes. At all sites from Figure 1, samples for major ion analysis were put into $60 \mathrm{~mL}$ Nalgene ${ }^{\mathrm{TM}} \mathrm{HDPE}$ sterile sample bottles using a $0.2 \mathrm{~mm}$ filter, preserved with a drop of nitric acid and stored at $0-10^{\circ} \mathrm{C}$. A Thermo Scientific 
Dionex ion chromatography system analyzed the samples, using a 1/25 dilution for the hydrothermal samples. Samples for analysis of $\mathrm{CO}_{3}$ and $\mathrm{HCO}_{3}{ }^{-}$were syringed into Falcon ${ }^{\mathrm{TM}} 50 \mathrm{~mL}$ Conical Centrifuge Tubes using a $0.2 \mathrm{~mm}$ filter. A MetrohmTM TitrandoTM 869 Compact Sample Changer Titrator ran the samples with $\mathrm{NaOH}$ as a standard to test for alkalinity, used to calculate $\mathrm{CO}_{3}$ and $\mathrm{HCO}_{3}^{-}$. Rockware AqQa software calculated the internal consistency of samples, cutting off anion-cation balances greater than $10 \%$, and plotting the data on a Piper diagram.

In order to examine the downstream effects of hydrothermal mixing, the Roseau River is a good fit as it is well sampled along its north fork and features three different hydrothermal areas (Fig. 1). Along the Roseau River, sample sites MI5, MI4, TR3, TR5, TR2, WW3.5, WW9, and WW10 were chosen and their distance upriver measured using GIS.

\section{RESULTS}

Of the 104 sample sites, a total of 279 samples were collected and analyzed, an average of 70 per year from 2014 to 2017. Out of all sample sites, 55 are classified as Met (13 west coast, 21 east coast, 21 other), 8 as coastal Hyd-met ( 7 west coast, 1 east coast), 18 as interior Hyd-met, and 22 as Hyd. One sample site near the Valley of Desolation hydrothermal area, VOD10, has an unknown exact location and is excluded from analysis.

\section{Climatic Factors}

Dominica's east coast is slightly more depleted in $\delta^{18} \mathrm{O}$ compared to the west coast, by $\sim 0.20 \%$ o $(\alpha=0.05)$ (Fig. 2). The difference in $\delta^{18} \mathrm{O}$ between coasts is consistent throughout 2014 to 2017 . However, if only meteoric streams are considered, then this difference is not statistically significant $(\mathrm{P}=0.07)$. There is no significant difference in $\delta^{2} \mathrm{H}$ between east and west coasts $(\mathrm{P}=0.80)$. Turning to annual trends over the four-year period and the possible influence of Tropical Storm Erika, there is a small, but consistent positive trend in $\delta^{18} \mathrm{O}$ of the purely meteoric samples, moving steadily from $-2.38 \%$ in 2014 to $-2.24 \%$ in 2017 .

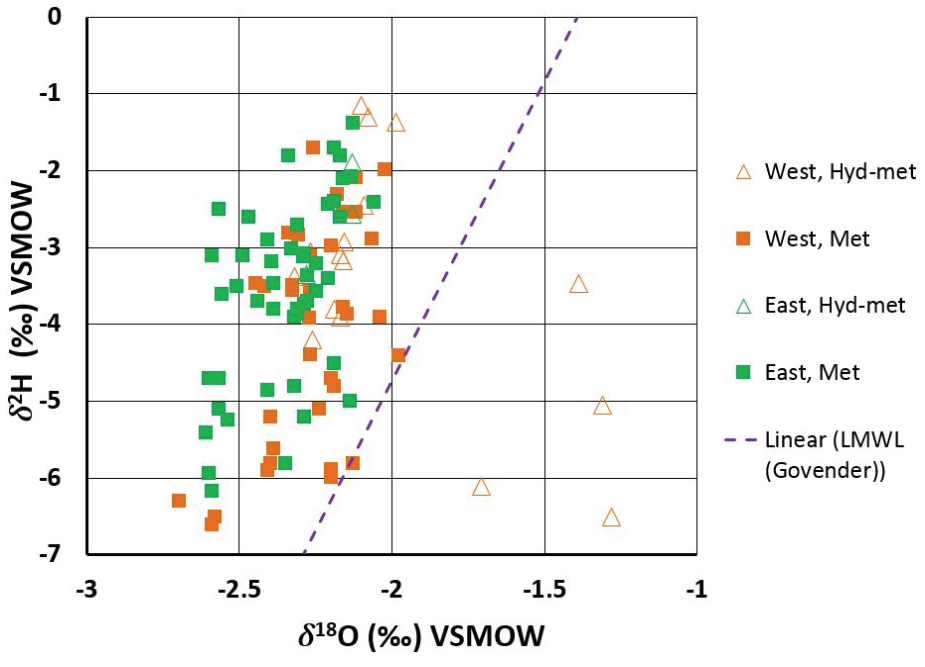

Figure 2. Graph of stable water isotopes showing difference between east and west coast sample sites. Note the lack of difference between Met samples.

Graphs were created to display $\delta^{18} \mathrm{O}$ in relation to mean catchment precipitation and mean catchment altitude. However, a statistical relationship does not exist between $\delta^{18} \mathrm{O}$ and mean catchment precipitation $\left(\mathrm{R}^{2}=0.0093\right)$, nor does one exist between $\delta^{18} \mathrm{O}$ and mean catchment altitude $\left(\mathrm{R}^{2}=0.0642\right)$.

\section{Hydrothermal Factors}

Isotopically, there are distinct differences between the four categories of hydrothermal input to water (Fig. $3)$. Purely meteoric streams are the least enriched in both $\delta^{18} \mathrm{O}$ and $\delta^{2} \mathrm{H}$, followed by interior Hyd-met, then coastal Hyd-met, then Hyd. The same trend is seen in respect to variability, with Met displaying the smallest standard deviation and Hyd the greatest. From a two-sample T-test assuming equal variances, interior streams with a known hydrothermal influence differ significantly from those without any known source in $\delta^{18} \mathrm{O}$, but not in $\delta^{2} \mathrm{H}(\alpha=0.05)$. The mean differences are $0.19 \%$ for $\delta^{18} \mathrm{O}$, and $0.46 \%$ for $\delta^{2} \mathrm{H}$.

Figure 4 displays a map of $\delta^{18} \mathrm{O}$ values. Spatially, values are seen to be more positive in the vicinity of hydrothermal sites, with the exception of more negative values in the Morne Aux Diables (MAD) volcanic center. Deuterium show a less obvious trend, though values are generally more positive directly at hydrothermal sites. 

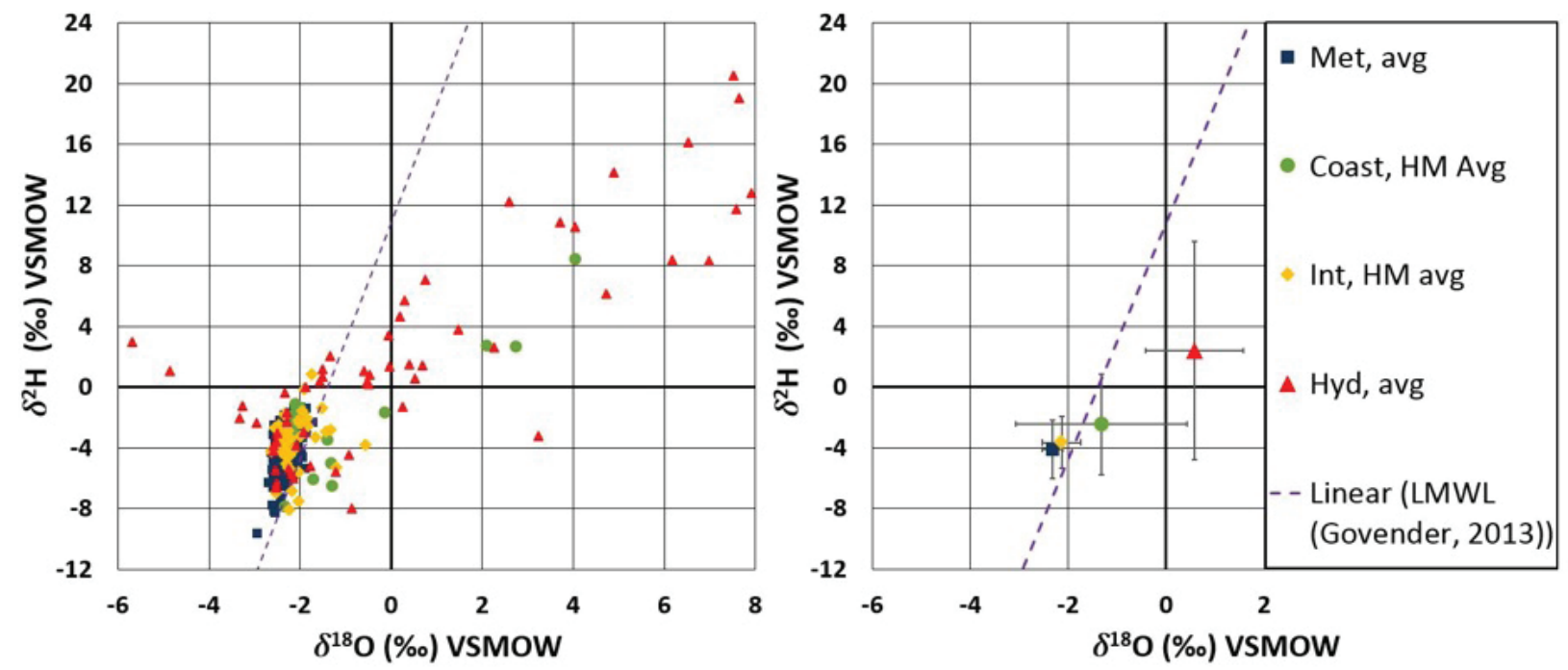

Figure 3. Stable water isotope graph split between hydrothermal categories. Left graph shows all data, right graph shows 4-year averages and standard deviations.

Piper diagrams show that stream waters sourced by hydrothermal springs are geochemically similar to their hydrothermal source, and generally contain more $\mathrm{SO}_{4}, \mathrm{Na}, \mathrm{Mg}$, and $\mathrm{Cl}$ (Fig. 5). Hydrothermal springs display the highest concentrations of these ions.
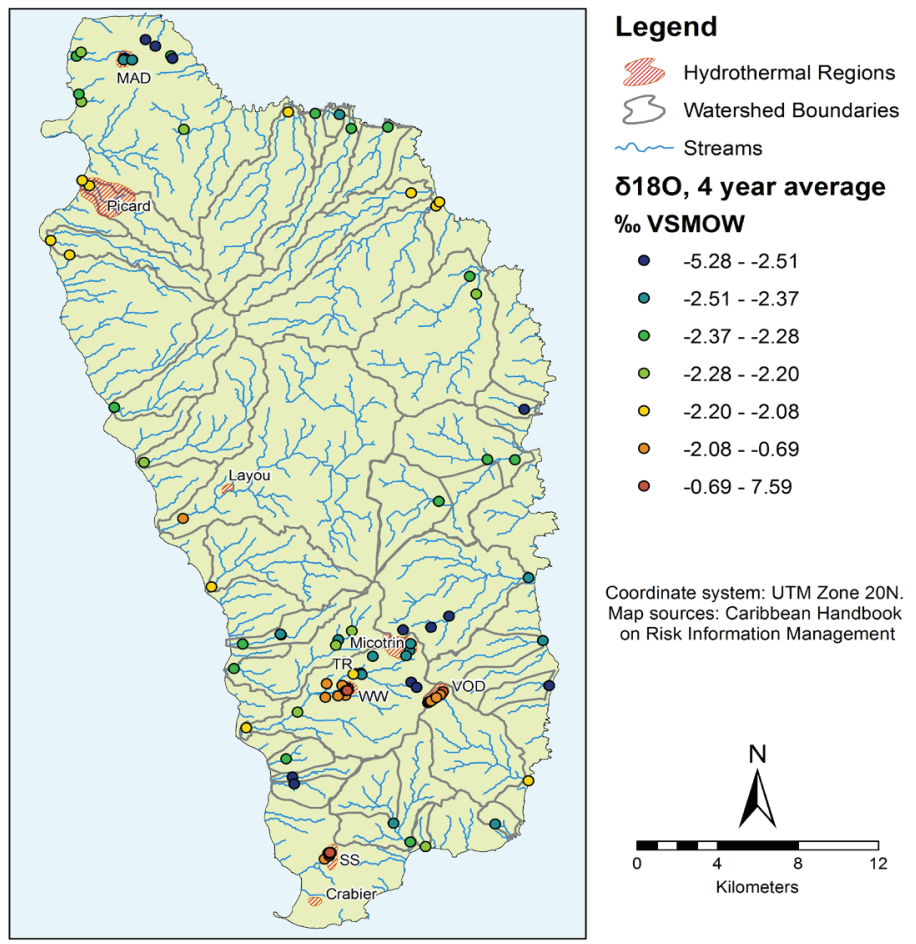

Figure 4. Map of $\delta^{18} \mathrm{O}$ values for all sample sites. Areas with any known degree hydrothermal contribution are generally mapped. $M A D=$ Morne Aux Diables, $W W=$ Wotten Waven, $V O D=$ Valley of Desolation, and SS = Sulphur Springs. Note: Trafalgar (TR) has very minor thermal contribution but is generally not considered to be hydrothermal.

\section{DISCUSSION}

\section{Climatic Factors}

Stable water isotope values show no significant difference between east and west coast, suggesting any differences in precipitation or dominant weather direction are not significant enough to alter stream water chemistry. This is supported by the lack of correlations between $\delta^{18} \mathrm{O}$ and either catchment parameter. It should be noted that the sampling period (June) has historically been the time of year when Dominica's east and west coast weather stations have been the most similar in precipitation (weather.gov.dm). If sampled during either May or November, when the east-west coast precipitation difference is most pronounced, then climatic effects may be more noticeable. A year-long study of Dominican stream waters revealed distinct chemical differences between the wet and dry seasons when corrected for precipitation difference with regards to dissolved ions (Goldsmith et al., 2009).

With regards to Tropical Storm Erika, no discernible effect is seen, with meteorically-fed streams staying on a consistent trend of positive shifts in $\delta^{18} \mathrm{O}$ and no deviation from this trend in 2016. Since sampling occurred 10 months following the storm, it is likely the residence times of meteoric waters are shorter than this period, and that severe weather events do not have long lasting island-wide effects on stream chemistry. However, to confirm this more research is needed, 


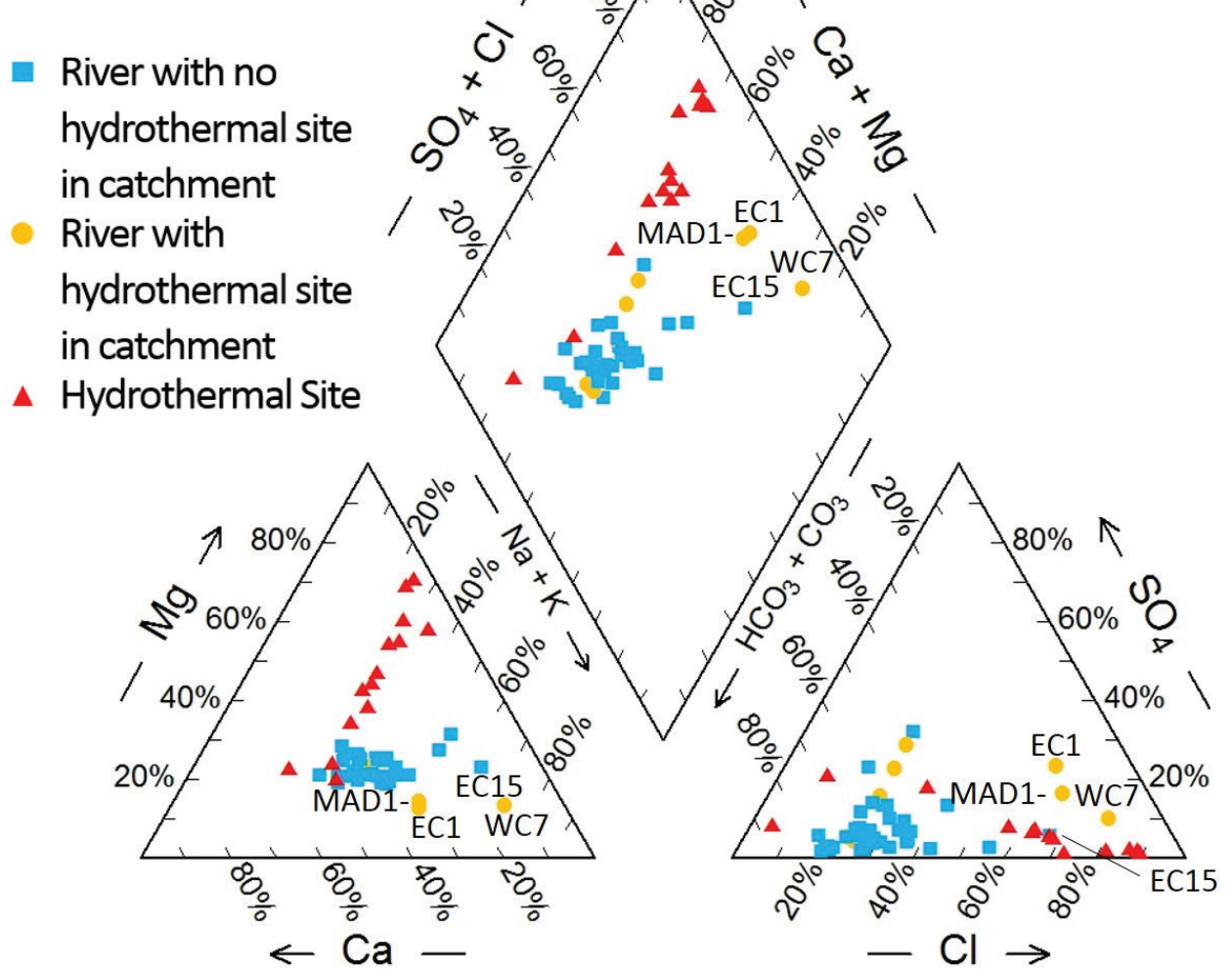

Figure 5. Major ion piper diagram, displaying Hyd, Hyd-met, and Met samples.

especially soon after storm events, on cases of stream water effects from storm events in the tropics. Recently, Hurricane Maria, a category 5 storm which was much more severe than Tropical Storm Erika, made landfall in Dominica in September 2017. A subset of stream waters were collected in January 2018, four months after the storm, and are currently being analyzed.

\section{Hydrothermal Factors}

Where stream water chemistry influences are most apparent is from the effects of mixing with hydrothermally altered waters. Figure 4 shows how streams downstream of hydrothermal sites also have ionic compositions between meteoric waters and their hydrothermal source, with the exception of higher $\mathrm{Na}+\mathrm{K}$ concentrations for some of the Hyd-met samples. This could be due to mixing of some sea water in coastal sampling, as $\mathrm{Na}+\mathrm{K}$ concentrations are high only in the case of a handful of coastal samples.
As expected, Figure 3 shows that waters generally become more enriched in both $\delta^{18} \mathrm{O}$ and $\delta^{2} \mathrm{H}$ with progressive input of hydrothermally altered water. As noted in previous Dominican stream chemistry reports, precipitation amount seems to be inversely correlated with $\delta^{18} \mathrm{O}$ in Hyd and Hyd-met samples, due to dilution of hydrothermally altered stream water with more meteoric waters (Metzger, et al., 2015; DeFranco, et al., 2016; Metzger, et al., 2016). This effect is not seen in Hyd samples. However, in 2017 this trend is not followed, as both precipitation and $\delta^{18} \mathrm{O}$ increases, suggesting that some other factor is influencing the overall isotopic signature of hydrothermal systems.

One peculiarity is that Hyd-met samples near the coast are more isotopically enriched than Hyd-met samples further inland, contrary to what would be expected due to progressive meteoric input downstream. However, interior Hyd-met are still contained within the variance of coastal Hyd-met. The few cases of coastal Hyd-met samples that significantly shift the average of the group in a more positive direction are the streams that drain the Sulphur Springs (SS) system near the south- 
western coast. Here, several explanations are possible, and it is likely a result of a combination of these factors. The proximity of downstream sample sites to both the coast and to the hydrothermal sites means that hydrothermal waters are not getting as much meteoric input before being sampled, evident in the orange color and high temperatures at the downstream sampling site. Another factor that could contribute in the decrease the meteoric input is that the location of SS on the southwestern coast means that this area receives less rainfall compared with the rest of the island. This may also mean that the system itself is more vapor dominated as compared to the others that appear to be more liquid dominated. Hence, its difference in stable isotope composition.

In a few samples hydrothermal sites display a significant negative trend in $\delta^{18} \mathrm{O}$, as in the case of the MAD volcanic center, situated in the north of the island. This trend is consistent for MAD and may be a result of $\delta^{18} \mathrm{O}$ exchange between the thermal waters with dissolved $\mathrm{CO}_{2}$, which takes place during equilibration in systems with high ratios of $\mathrm{CO}_{2}$ to water (Joseph et al., 2011). In the case of rivers draining MAD, they show no deviation from nearby Met streams.

Looking at the spatial variation in isotopes, trends in $\delta^{18} \mathrm{O}$ are expected, with samples downstream of hydrothermal sites showing $\delta^{18} \mathrm{O}$ values similar to the hydrothermal source. There also appears to be a spatial component of enrichment. Near the Wotten Waven (WW) hot springs, there are enriched $\delta^{18} \mathrm{O}$ values nearby the hot springs that are not downstream (samples TR1 and WW6-8). This suggests that the movement of hydrothermal waters may not be limited to the hot springs, but that there is unknown subsurface input of hydrothermal waters to the nearby streams. Goldsmith et al. (2010) suggest similar conduits from soil/ bedrock interface to stream water. Locally in Wotten Waven, this release of hydrothermal waters could be due to faulting related to the underlying caldera and should be investigated further.

\section{CONCLUSIONS}

Based on these results, precipitation and weather factors do not play a significant role in stream chemistry. However, more sampling is needed throughout the year to examine the effects of seasonal variation.
In our sampling period, hydrothermal sources are the dominant control on stable isotope and ionic composition. Streams draining hydrothermal sources are isotopically and ionically enriched. Input of hydrothermal waters to streams may not be limited to surface features such as springs, but may also be contributed from complex groundwater sources directly to streams from underlying hydrothermal reservoirs.

\section{ACKNOWLEDGEMENTS}

This material is based upon work supported by the Keck Geology Consortium and the National Science Foundation under Grant No. 1659322. I would also like to thank Sue Swanson for her guidance, MaziMathias Onyeali, Jackie Buskop, Amanda Schmidt, Sarah Katz, and Matt Manon for help with lab and field work. Thank you to the Archbold Tropical Research and Education Center and Union College for hospitality and facilities.

\section{REFERENCES}

DeFranco, K., Frey, H.M. and Manon, M.R.F., 2016, Establishing island-wide water characterization in a volcano-hydrothermal system in Dominica, Lesser Antilles: Northeastern section Geological Society of America Abstracts with Programs. v. 48 , no. 2 .

Dominica Meteorological Service, 2018, DouglasCharles Airport: 1981-2010 and Canefield Airport: 1982-2011: http://www.weather.gov.dm/ climate-data.

Goldsmith, S.T., Carey, A.E., Johnson, B.M., Welch, S.A., Lyons, W.B., McDowell, W.H., and Pigott, J.S., 2010, Stream geochemistry, chemical weathering and $\mathrm{CO}_{2}$ consumption potential of andesitic terrains, Dominica, Lesser Antilles: Geochimica et Cosmochimica Acta, v. 74, p. 85-103, doi: 10.1016/j.gca.2009.10.009.

Good, S.P., Mallia, D.V., Lin, J.C., and Bowen, G.J., 2014, Stable Isotope Analysis of Precipitation Samples Obtained via Crowdsourcing Reveals the Spatiotemporal Evolution of Superstorm Sandy: PLOS ONE, v. 9, p. e91117, doi: 10.1371/ journal.pone.0091117. 
Govender, Y., Cuevas, E., Sternberg, L.D.S., and Jury, M.R., 2013, Temporal Variation in Stable Isotopic Composition of Rainfall and Groundwater in a Tropical Dry Forest in the Northeastern Caribbean: Earth Interactions, v. 17, p. 1-20, doi: 10.1175/2013EI000534.1.

Johnson, L., Richards, C., Host, G. and Arthur, J., 1997, Landscape influences on water chemistry in Midwestern stream ecosystems: Freshwater Biology, v. 37, p. 193-208. doi:10.1046/j.1365-2427.1997.d01-539.x

Joseph, E.P., Fournier, N., Lindsay, J.M., and Fischer, T.P., 2011, Gas and water geochemistry of geothermal systems in Dominica, Lesser Antilles island arc: Journal of Volcanology and Geothermal Research, v. 206, p. 1-14, doi: 10.1016/j.jvolgeores.2011.06.007.

Lachniet, M.S., and Patterson, W.P., 2009, Oxygen isotope values of precipitation and surface waters in northern Central America (Belize and Guatemala) are dominated by temperature and amount effects: Earth and Planetary Science Letters, v. 284, p. 435-446, doi: 10.1016/j. epsl.2009.05.010.

Lang, D.M., 1967, Soil and land-use surveys No. 21. Dominica., in Report. Regional Research Centre, University of the West Indies, Dominica, p. 59.

McDowell, W.H., Lugo, A.E., and James, A., 1995, Export of Nutrients and Major Ions from Caribbean Catchments: Journal of the North American Benthological Society, v. 14, p. 12-20, doi: 10.2307/1467721.

Metzger, T., Frey, H.M., and Manon, M.R.F., 2015, Water geochemistry analysis of streams and hydrothermal waters in Dominica, Lesser Antilles: Northeastern section Geological Society of America Abstracts with Programs, v. 47.

Metzger, T., Frey, H.M., Manon, M.R.F., and

DeFranco, K., 2016, Island-wide isotopic analysis of meteoric and hydrothermal waters in Dominica, Lesser Antilles: Geological Society of America Abstracts with Programs. v. 48, no. 7.

Ogden, F.L., 2016, Evidence of equilibrium peak runoff rates in steep tropical terrain on the island of Dominica during Tropical Storm Erika, August 27, 2015: Journal of Hydrology, v. 542, p. 35-46, doi: 10.1016/j.jhydrol.2016.08.041.
Smith, A.L., Roobol, M.J., Mattioli, G.S., Fryxell, J.E., Daly, G.E., and Fernandez, L.A., 2013, The Volcanic Geology of the Mid-Arc Island of Dominica: Geological Society of America, Geological Society of America Special Paper, https://books.google.com/ books?id=FbmkAQAAQBAJ. 